\title{
Dialogue
}

http://journals.cambridge.org/DIA

Additional services for Dialogue:

DIALOGUE

Email alerts: $\underline{\text { Click here }}$

Subscriptions: $\underline{\text { Click here }}$

Commercial reprints: $\underline{\text { Click here }}$

Terms of use : $\underline{\text { Click here }}$

\section{Factualism, Normativism and the Bounds of Normativity}

\author{
Thomas M. Besch
}

Dialogue / Volume 50 / Special Issue 02 / June 2011, pp 347 - 365

DOI: 10.1017/S0012217311000308, Published online: 21 October 2011

Link to this article: http://journals.cambridge.org/abstract_S0012217311000308

How to cite this article:

Thomas M. Besch (2011). Factualism, Normativism and the Bounds of Normativity. Dialogue, 50, pp 347-365 doi:10.1017/S0012217311000308

Request Permissions : $\underline{\text { Click here }}$ 


\section{Factualism, Normativism and the Bounds of Normativity}

THOMAS M. BESCH University of Sydney

ABSTRACT: The paper argues that applications of the principle that "ought" implies "can" (OIC) depend on normative considerations even if the link between "ought" and "can" is logical in nature. Thus, we should reject a common, "factualist" conception of OIC and endorse weak "normativism." Even if we use OIC as the rule "cannot'therefore 'ought not'," applying OIC is not a mere matter of facts and logic, as factualists claim, but often draws on "proto-ideals" of moral agency.

RESUME: Cet article défend que les applications du principe " "devoir" implique "pouvoir"” (OIC pour l'anglais 'ought' implies 'can') dépendent de considérations normatives quoique ce lien soit de nature logique. Nous devrions donc rejeter la conception "factuelle» de l'OIC et plutôt défendre un «normativisme» faible. Même en supposant que l'on utilise l'OIC comme étant la règle " "ne pas pouvoir" implique "ne pas devoir"”, appliquer l'OIC n'est pas seulement une question de faits et de logique, comme le soutiennent les "factualistes», mais découle souvent de "proto-idéaux» de l'agentivité morale.

\section{Introduction}

The principle that "ought" implies "can" (or OIC) continues to play an important role in everyday normative debate. Where demands, principles, requirements, standards, or, more generally, normative views, prescribe what cannot be done or be brought about, there, it is often assumed, trumping objections are in place. Moreover, such objections are often taken to be drawing on a constraint that all reasonable normative debate must meet, rather than to be expressing,

Dialogue 50 (2011), 347-365.

(C) Canadian Philosophical Association/Association canadienne de philosophie 2011 doi: $10.1017 / \mathrm{S} 0012217311000308$ 
say, a reasonably controversial normative demand. Despite the fundamental role that OIC is often awarded, though, OIC is the subject of disputes where it is made the focus of discussion in its own right. One dimension in which such disputes arise concerns the link between "ought" and "can." Does "ought" entail or at least presuppose "can"? Or is the link, as some argue, extra-logical in nature? ${ }^{1}$ A second dimension concerns the systematic status of OIC. Is OIC a meta-ethical principle that neutrally ranges over all ethical codes, or does it, as some insist, express a kind of ethical commitment in its own right? Two further dimensions are less prominent, but no less important. Third, then, what kind of "can" does OIC invoke? Even where we agree about the logic and status of OIC, we still can disagree about what sort and level of physical, psychological, intellectual, or other limitations allow an inference from "cannot" to "not ought." A closely related fourth dimension concerns the nature of the usage we make of OIC. OIC is often applied as a rule such as "cannot therefore not ought," or as a tool to comb out "oughts" that run up against (alleged) facts about human limitations - in a way, that is, that treats these (alleged) facts as given and fixed, rather than vice versa, and that takes the application of OIC to be a matter of facts and logic. But should we think of OIC in such, say, factualist terms? People can reasonably disagree about what kind of "cannot" gives OIC sufficient grip, and such disagreement often is not about facts or logic, but invokes genuine normative issues. But if that is so, it would seem, factualism, or at least pure forms of factualism, cannot fully capture the nature of the usage we make of OIC.

My discussion will in the first instance focus on the second, third, and fourth dimensions. The main aim of my discussion is to suggest that non-trivial applications of OIC significantly depend on normative, if not ethical, considerations even if we plausibly assume that the link between "ought" and "can" is logical in nature. That is, even if OIC is a logical principle, non-trivial applications of OIC will tend to cut across the meta-ethical and the first-order ethical. In fact, they often draw on what I shall call "proto-ideals." This, we shall see, suggests that the factualist view of OIC is misguided in an important respect. It might be right to use OIC as the rule "cannot therefore not ought." Even so, applying OIC is not simply a matter of facts and logic: there are normative, and sometimes ethical, considerations in play where we decide that a given "cannot" is of the appropriate kind to give OIC sufficient grip. To make this case, I will assume that the link between (prescriptive, choice-guiding) "oughts" and "can" is logical, and, more precisely, presuppositional in nature (I will elaborate on this later). My case does not depend on this reading of OIC, however, as its main focus is not on the link between "ought" and "can" but rather on the sort of considerations that come into play in determining what kind of "can" or "cannot" suits the purposes of OIC.

In section 2, I shall distinguish between a factualist conception of OIC and its polar opposite, namely, what I shall dub "normativism." A rejection of pure normativism will then set the stage for the search for a more modest form of 
normativism that escapes the problem of pure normativism but goes beyond factualism in elevating the role normative considerations play in the application of OIC. Section 3 elaborates on the presuppositional view of OIC, and asks what kind of "can" is presupposed by "ought." While "ought" always presupposes the "can" of logical possibility, I shall argue, non-trivial applications of OIC can, and inevitably do, suppose richer and practically more relevant forms of "can." As sections 3 and 4 suggest, the question of what kind of "can" we should suppose in our usage of OIC often is an ethical question. In fact, I shall submit, this question is linked to the complex ethical theme of what proto-ideals we require agents to live up to in order to qualify as genuine participants in the pursuit of doing right and being good. Against this background, finally, section 5 suggests a modest form of normativism - a view, that is, that does not reject the idea that we may employ OIC as the rule "cannot therefore not ought," but that takes it that the bounds of normativity must be determined at least partly on normative, and in many cases ethical, grounds. ${ }^{2}$

\section{Two Doxastic Policies}

While OIC might play various roles in normative discourse and practice, at a more general level it seems to have a simple doxastic upshot. It requires our normative conceptions - that is, our views of what ought to be done or brought about, widely conceived - to cohere with our factual conceptions of what can or cannot happen, or be brought about, and in particular our views of human limitations. In meeting this requirement, however, different doxastic policies can be, and have been, applied. Consider the following exchange:

Paul: For all the reasons that I can see, Peter really ought to do it!

Betty: But Peter can't do such a thing. So be reasonable: accept that your "ought" should give way.

Paul: I disagree. He really ought to do it. And since that is so, he is able to do it.

Betty rejects the purported "ought" in the light of the reasons she sees for the view that Peter cannot carry out the act in question. Paul reverses this order: he rejects the view that Peter cannot do the thing in question in the light of the reasons he sees for the view that Peter ought to do that thing. If we set questions of plausibility aside, both doxastic policies mark possible (though perhaps not equally reasonable or plausible) ways to apply OIC to conflicts between an "ought" and a "cannot." OIC, like other conditionals, is doxastically bi-directional. If " $\mathrm{X}$ ought to $\varphi$ " holds only if and when " $\mathrm{X}$ can $\varphi$ " holds, then reasons to believe that $\mathrm{X}$ cannot $\varphi$ are indirect reasons to believe that it is not the case that $X$ ought to $\varphi$, while reasons to believe that $X$ ought to $\varphi$ are indirect reasons to believe that $X$ can $\varphi$. At least in principle, then, we could implement OIC in two ways. On the one hand, we could implement the principle (i) by way of assessing, or, if necessary, adjusting or revising, "oughts" in 
the light of our reasons to endorse views of what cannot be done or be brought about. On the other hand, we could implement it (ii) by way of assessing, or, if necessary, adjusting, or revising, our factual views of what agents cannot do or bring about by the light of our reasons to endorse the relevant "oughts." To use a term that surfaced above already, let us refer to (i) as a factualist doxastic policy; as to (ii), we might call it a normativist doxastic policy.

A note on these two policies is in order. Factualism in effect reads OIC from the perspective of the "can," and so assesses and shapes "oughts" in the light of certain factual conceptions such as views of human nature or of human limitations. Thus, the factualist policy in effect employs OIC as a maxim such as:

FP: As it is not the case that $\mathrm{X}$ ought to $\varphi$ if $\mathrm{X}$ cannot $\varphi$, we should not assume that $X$ ought to $\varphi$ if there is good reason to believe that $X$ cannot $\varphi$. (Thus, a pure form of factualism in effect employs OIC as the rule "cannot therefore not ought.")

On this doxastic policy, reasons to assume that something cannot be brought about are treated as reasons to assume that it cannot be prescribed, demanded, required, and so forth. To put matters bluntly, factualism thus circumscribes the realm of intelligible "oughts" - and, as a subset of these, authoritative "oughts"- by factual conceptions, such as factual conceptions of the human condition or of human limitations. In a sense, then, factualism subjects normative conceptions to a test of compatibility with factual views, and so takes the bounds of normativity to be shaped by the factual.

Factualism looks like a fairly familiar stand. Most of us are factualists at least some of the time. Of course, ordinary normative disputes more often concern the appropriateness, grounds, and consequences of normative views, rather than their intelligibility. And where people insist that something is demanded of them that they cannot do, this might not always tacitly or openly invoke OIC, but might instead express the view that the relevant demands have unacceptable implementation costs. Still, factualism appears to be a widely followed doxastic policy, both in practice and in theory. E.g., most of us grant that there are psychological and physical limits to our capabilities and powers that require us to waive or suspend otherwise authoritative demands - whatever moral outlook we might otherwise endorse. And where moral theories are rejected for placing demands on deliberation, motivation, or agency, that ordinary people cannot live up to, there often is a commitment to some form of factualism in the background. ${ }^{3}$ Note, though, that factualism as I understand it here is not simply the idea that human capacities and powers set limits to what can reasonably be demanded of human agents. Rather, it involves the idea that the setting of these limits is a factual matter and, accordingly, that we can identify those limits on non-moral grounds.

Turning now to the normativist stand, it in effect reverses the factualist order of priority. Rather than assessing normative conceptions in light of their compatibility with factual conceptions, normativism assesses, develops, adjusts, or 
revises factual conceptions in light of their compatibility with normative conceptions (or at least some, especially privileged normative, conceptions). On the normativist stand, then, we subject factual conceptions to a test of normative acceptability. Normativism thus employs OIC as a maxim such as:

NP: As it is the case that if $X$ ought to $\varphi$, then $X$ can $\varphi$, we should not assume that $X$ cannot $\varphi$ if there is good reason to believe that $X$ ought to $\varphi$. (Thus, pure normativism would in effect employ OIC along the lines of "ought therefore can.")

Thus, it would express a normativist stand to argue that we should not accept views of human beings, or of the human condition, or of human limitations, that, given OIC, would render (allegedly) authoritative, fundamental "oughts" inapplicable to us. ${ }^{4}$ For instance, normativists might reason from the view that we owe to others some degree of impartiality to a rejection of conceptions of human agency according to which people are incapable of showing even minimal forms of altruism. Normativism, then, treats (some) factual conceptions not as limiting, but as limited by, (some) normative conceptions. Thus, it takes it that the bounds of normativity are not, or not always, shaped by the factual.

Now, at first sight, there is an aura of unreasonableness about normativism — or at least pure forms of normativism. True, if "ought" implies "can," then there is a sense in which reasons to believe that X ought to $\varphi$ are indirect reasons to believe that X can $\varphi$. But it does not follow that the presence of such reasons allows us to transit from "X ought to $\varphi$ " to "X can $\varphi$." This is so because these reasons cannot simply be treated as trumping if and where there are other, standing reasons to believe that X cannot $\varphi$. E.g., if Peter believes that Paul ought to save Jane from drowning, but there are reasons to believe that Paul is unable to do so - say, Paul is known to have a heart condition that will physically incapacitate him if he attempts to save her-then these reasons hold whether or not Peter also sees reasons for the "ought" in question. Prior to further argument, then, we may not transit from "Paul ought to save Jane" to "Paul can save Jane" (or "It is not the case that Paul cannot save Jane") in this case. To generalize, even if we have good reasons to believe that X ought to $\varphi$, we should, if and where there are standing reasons to believe that $X$ cannot $\varphi$, follow the factualist doxastic policy, if any. However, if that is right, then normativism seems to drop out of the picture entirely. After all, for there to be a meaningful opportunity to follow either factualism or normativism in the application of OIC, there would need to be a meaningful, non-superficial conflict between some views of what ought to be done and some views of what cannot be done. But in order to have that kind of conflict, there would have to be reasons of some relevant, at least initially credible sort in favour of both kinds of views involved in the conflict-including, as it were, the relevant factual views. And thus it seems that there would have to be standing reasons of the overall sort that block the transition from "Paul ought to save Jane" to "Paul 
can save Jane" in our example. It hence seems that wherever normativism could meaningfully come into play, we should follow not the normativist doxastic policy, but the factualist policy. As it stands, therefore, normativism would seem to both be unreasonable and irrelevant.

\section{"Ought" and "Can"}

Even if a pure form of normativism of the sort expressed by NP is defective, there still might be plausible middle ground between normativism and factualism that significantly elevates the role normative conceptions play in our application of OIC. To identify such middle ground, I shall suggest, we should focus on the vexing issue of "can"-rather than the "ought," or the link between "ought" and "can." Still, to fix ideas, it is best to prefix things with a brief statement of what, for my present purposes, I shall take to be the nature of OIC. Following Hare, I will (plausibly, I believe) assume that a presuppositional interpretation of OIC is accurate-at least for the case of prescriptive ultima facie "oughts." I hasten to add, though, that my case will be available even if we reject such an interpretation as long as we accept that OIC is true on some interpretation. Thus, I shall not defend a presuppositional view of OIC. Instead, I simply shall use it as a background for my case.

A presuppositional, Hare-type view of OIC comes down to this..$^{5}$ The relation between (prescriptively used) "oughts" and "can" is one not of conversational implicature or, more strongly, of entailment, but more like the relation between "The King of France is bald" and "There is a King of France." The claim "The King of France is bald" can be true or false of the King of France only if there is a King of France. If there is no King of France, then one of the existential presuppositions of that claim is not fulfilled: the claim is not just false, but unintelligible. Accordingly, we might (vaguely) say that "X can $\varphi$ " expresses a presupposition of the intelligibility of "X ought to $\varphi$." If X cannot $\varphi$, then "X ought to $\varphi$ " is not false but unintelligible, and so must be denied externally: the "cannot" is a reason to believe not that X ought not to $\varphi$, but that it is not the case that $\mathrm{X}$ ought to $\varphi$ - the negation involved here does not alter the content of the prescription but, rather, negates the prescribing. ${ }^{6}$ Accordingly, as much as a reasoner cannot reasonably ask whether the King of France is bald (or offer an answer to this question) unless she supposes that there is a King of France, she cannot, or not prior to further argument, reasonably raise the question of whether $\mathrm{X}$ ought to $\varphi$ (or offer an answer to this question) unless she supposes that $\mathrm{X}$ can $\varphi .^{7}$

Now, this leaves out something that is crucial for our purposes. If "ought" presupposes "can," then the way it does so is more complex than the way in which "The King of France is bald" presupposes "There is a King of France." This complexity stems partly from the opacity of the verb "can." Different interpretations can be attached to this verb, each lending different modal strengths to claims of the form "X can $\varphi$," thereby requiring different thresholds to be 
met for "X can $\varphi$ " to be true. On a suitable interpretation of "can," for instance, "X can $\varphi$ " would be true in any of the following scenarios:

(i) X's ping is a logically possible event (or, say, X's ping is coherently conceivable);

(ii) X's ping is an empirically possible event (i.e., it would not contradict the known regularities of nature);

(iii) $\mathrm{X}$ is physically fit to $\varphi$;

(iv) $\mathrm{X}$ is psychologically (mentally, emotionally) capable of $\varphi$ ing;

(v) $\mathrm{X}$ can become someone who would $\varphi$ if necessary;

(vi) $\mathrm{X}$ will $\varphi$ if she sees a reason to;

(vii) the costs of $\varphi$ ing for $\mathrm{X}$ are not unacceptably high.

Accordingly, both "X can $\varphi$ " and "X cannot $\varphi$ " can simultaneously be true of $\mathrm{X}$ - namely, on different interpretations of the verb "can." Betty might physically be fit to walk to the middle of the market square, and thus she can do so in the senses of (i), (ii), (iii), and, let us assume, (vii), while her agoraphobia renders her unable to exercise that ability, and thus she cannot do so in the senses of (iv) and (vi), even though (v) might be true of her. The above list of scenarios that can render claims like " $\mathrm{X}$ can $\varphi$ " true of course is not exhaustive. At the bare minimum, for it to be true that $X$ can $\varphi$ would seem to require that it is logically possible for $\mathrm{X}$ to $\varphi$. Maximally, it might require something to the effect that $\mathrm{X}$ is prepared and ready to $\varphi$. But there is much space between the extremes of logical possibility on one side, and utter readiness on the other. Correspondingly, there are many kinds and shades of impossibility, inability, limitation, or finitude that could reasonably be taken to render "X cannot $\varphi$ " true of $X$.

These things are fairly platitudinous, and they have been observed before. That they nevertheless matter here is owed to the less obvious lesson that the entail. Kekes, for instance, writes:

"Ought implies can" will here be . . interpreted as follows: a person is morally obliged to do something only if it is in her power to do it or not do it. . . What exactly is in one's power to do is unclear. It is obvious that doing what is logically or physically impossible is not in one's power. But there are other constraints as well. Physical and mental limitations peculiar to a person may also impose unavoidable limitations. Unobservant people cannot respond to subtle clues, dilettantes cannot have depth, and the lethargic cannot be quick on the uptake. What individual limitations are unavoidable is controversial. (459)

Kekes then goes on to tell us that he seeks to "sidestep this issue" in order to "simply say that, in addition to logical and physical impossibility, there are also unavoidable personal limitations on one's power." Kekes is certainly right 
in his conclusion; yet, if we are interested to determine whether and how OIC can have ethical content, we should not sidestep this issue. ${ }^{8}$ Instead, we should recognise that there are various interpretations that can be attached to claims like "X can $\varphi$ " and "X cannot $\varphi$ "- or, as the above passage puts it, to " $\mathrm{X}$ has (does not have) the power to $\varphi$ "-and, correspondingly, that it is possible for reasonable people to agree that X can (or cannot) $\varphi$, but to disagree as to whether "X ought to $\varphi$ " is intelligible, if and where they disagree whether the sense in which X can (or cannot) $\varphi$ is of the appropriate kind.

What kind of "can" (or "cannot") would it be appropriate to suppose in a given context? For now, let us consider what kind of "can" (or "cannot") it would be unreasonable not to suppose in all normative contexts - that is, whatever answer to the question just asked we would be inclined to give. Whatever our answer to that question, then, it would seem that we cannot reasonably reject the following view (we might dub it the "trivial conception," or "TC"):

TC: One cannot intelligibly claim that $X$ ought to $\varphi$ unless it is, or at least one takes it to be, logically possible for $\mathrm{X}$ to $\varphi$ (in the sense that the claim "X can $\varphi$ " is not semantically inconsistent).

It is at least in the sense of TC that the relation between "X can $\varphi$ " and " $X$ ought to $\varphi$ " is as tightly knit as the relation between "There is a King of France" and "The King of France is wise." As much as "The King of France is wise" could not possibly be true unless there is a King of France, it could not possibly be the case that $\mathrm{X}$ ought to $\varphi$ unless it is logically possible for $\mathrm{X}$ to $\varphi$. To be intelligible, then, "X ought to $\varphi$ " must at least prescribe the logically possible.

Of course, your claim that $\mathrm{X}$ ought to $\varphi$ (or should have acted accordingly, or is blameworthy for failing to $\varphi$, and so on) will almost always give your hearers to understand that you believe that X's ping is possible not just in the thin sense of being a logically possible event, but in a richer, practically relevant sense. And if what is prescribed can happen in the sense of being logically possible only — as opposed to, e.g., being within what is, or at least should be, the agent's reach - the reasonableness of the prescription will almost certainly be contested. This is so especially where others expect us to raise our normative claims in order to guide, inform, or influence the actual choices of real people. Nevertheless, while logical possibility puts the threshold for the appropriate kind of "can" not nearly high enough, at least not for the purposes of guiding choices, there can be, and is, reasonable disagreement over how high or low that threshold should be placed. Again, I might assume that "Paul ought to save Jane from drowning" requires merely that Paul's saving of Jane would not defy the known regularities of nature-whether or not Paul is physically and psychologically fit to save her. You might assume that this puts the threshold too low, and that Paul "can" save Jane in the relevant sense only if he is 
physically (or physically and psychologically) fit to do so, and not otherwise forced not to do it. Even empirical possibility seems to be a threshold that could reasonably be seen as too high, and that hence is a possible subject of reasonable disagreement. Accidental conflicts between moral norms can make it empirically impossible for the agent to abide by all authoritative norms that apply in a given situation. And it is at least not obviously unintelligible to claim that one ought to act, or ought to have acted, on each of these conflicting norms. To say the least, as Montefiore emphasizes, seeing oneself as blameworthy for failing to act on both of two conflicting norms is not unusual-and this seems to reflect that "oughts" are not always taken to be unintelligible just because it is empirically impossible to act on them. ${ }^{9}$ Moreover, there can be moral doctrines that advance tragic norms - logically possible normative views, that is, that are taken to prescribe the impossible, but are nevertheless accorded authority and treated as standards by which the moral qualities of agents are to be assessed (e.g., consider a maxim such as "We ought to be without sin" advanced by a doctrine that takes it that everyone is necessarily and inescapably tainted by sin). Perhaps such tragic norms might be defective in a range of ways, e.g., they might be ineffective, pointless, imprudent, redundant, oppressive, or even cruel, but, again, it would seem that they are not, at least not obviously, unintelligible. ${ }^{10}$

The following might help to structure things. We can distinguish between (i) the "can" that "ought" presupposes as a matter of logic (at least given the hypothesis that there is such a matter of logic) and (ii) the "can" that "ought" presupposes from the point of view of potentially controversial, more substantive conceptions of the presuppositions of normative claims. Accordingly, we can distinguish between $\left(i^{*}\right)$ a "cannot" that necessarily waives demands, i.e., the "cannot" of logical impossibility, and (ii*) richer, practically more relevant "cannots" that count as demand-waivers from the point of view of conceptions of the sort just referred to. Conceptually, or as a matter of logic, "ought" presupposes the "can" of logical possibility. This is the platitude that TC states. Yet in conceptional respects-i.e., in the respect of competing conceptions of the sort of "can" that "ought" requiresthere can be different candidates for the role of the appropriate kind of "can." By the light of such conceptions, normative claims might have to be waived if what they prescribe is logically possible but "cannot" be done in some richer, practically more relevant sense. For simplicity's sake, let us also distinguish between demand-enablers and demand-waivers. Wherever we take "oughts" to require any particular kind of "can," we imply conceptions of demand-enablers and demand-waivers. For instance, if we take it that " $\mathrm{X}$ ought to $\varphi$ " requires that it is empirically possible for $\mathrm{X}$ to $\varphi$, we treat empirical possibility as a demand-enabler and empirical impossibility as a demandwaiver; similarly, where we take "oughts" to require physical or psychological ability, we treat the presence of this ability as a demand-enabler and its absence as a demand-waiver. 


\section{OIC and Proto-Ideals}

To sum up, the above suggests an important limitation of factualism. We have in effect seen that inferences like

(1) $X$ cannot $\varphi$.

(2) Hence, it is not the case that X ought to $\varphi$.

are problematic where the "cannot" in (1) is the "cannot" not of logical impossibility but rather of a richer, practically more relevant kind. In such cases, (2) does not follow unless a suitable conception of demand-waivers is supplied, as in:

(1) X cannot $\varphi$;

$\left(1^{*}\right) \mathrm{X}$ is unable to $\varphi$ in a way that is significant (relevant, decisive, fundamental) enough to pass the threshold of a demand-waiver.

(2) Hence, it is not the case that $X$ ought to $\varphi$.

Even if we accept (1), can we reject (2) if we dispute the appropriateness, relevance, or authority of $\left(1^{*}\right)$. Agreement about logic and the relevant facts, then, does not commit us to agreement about which "oughts" OIC combs out as unintelligible - that is, even if we apply OIC along factualist lines. Such agreement requires, as well, that we share suitable conceptions of demandwaivers. To suggest otherwise is a key shortcoming of factualism.

Now, what kinds of inabilities, limitations, or finitudes would be significant enough to waive or suspend "oughts"? How high (or low) should we place the threshold of demand-waivers? What levels of human capacity, skill, or development should we adopt as demand-enablers, thus taking them to mark prerequisites for the application of "oughts"? And should we endorse the same set of demand-waivers and demand-enablers for all "oughts," or different sets for different types of "oughts" - depending on, e.g., the contents of "oughts," their moral importance, or the likely consequences of waiving them? What we have seen so far suggests that such questions cannot be answered merely on grounds of whatever factual reasons we have in the first place to believe that X can or cannot $\varphi$. For the issue raised by these questions is not whether $\mathrm{X}$ really can or cannot $\varphi$, or in what ways, if any, $X$ can or cannot $\varphi$ : these questions remain open even if a sound and comprehensive factual understanding of what agents can or cannot do is at hand. Rather, the issue raised by these questions is whether the relevant facts should be accorded a certain status-namely, the status of demand-enablers or demand-waivers. This brings in a normative issue, and this is so not just because those questions cannot be answered on grounds of logic and facts alone. This is so also in other, more substantive ways. At least in the case of ethical "oughts," our conceptions of demandenablers and demand-waivers are an important part of what determines how 
high or low we set our most fundamental standards of conduct, and this impacts not only how we construe of these standards, but also what we expect of ourselves and others. At the same time, such conceptions enshrine a view of what agents ought to bring to the pursuit of doing right and being good-a view, that is, that appears to be ethical in own right.

To elaborate, consider Cooper's views. In a related context, he distinguishes between "impossibility," or, roughly, things that we cannot do whatever extra effort or support are invested, and "very great difficulty," or things that are nearly impossible in this sense, and writes:

If impossibility excuses, one would expect near impossibility to almost excuse, or at least to be a mitigating circumstance. For there is only a small gap between impossibility and very great difficulty. Moreover, if something is very difficult, it may be impossible always to succeed in doing it and therefore it would be unreasonable always to require it. ... We have to avoid setting our standards either too high or too low. If we set them too high, it will be just as objectionable as if we had recommended what was impossible, especially if what is difficult seems impossible or is impossible, if not for all, at any rate for most. If, on the other hand, we set our standards too low, there will be no incentive to try to do what is desirable, though difficult. Hence we need a distinction between the required and the desirable, between rules and ideals. . . . Now if we are to steer between these two extremes of too high standards and too low, we require both knowledge and judgment. If we are to know what we may rationally prescribe by rules or set up as ideals, we must already know what sort of people we are dealing with, what their characters are, what they are capable of, what as a matter of fact will be the effect of our recommendations on them. (50)

Much of this points in a good direction (even though it underestimates the extent to which the issue is normative). As Cooper in effect suggests, where acting on "oughts" would require capacities, skills, or qualities, that go beyond a level of human development that, we take it, people may be expected to bring to the pursuit of doing right and being good - that is, the pursuit of integrity, or of moral agency - there we often see "oughts" as articulating ideals, rather than as requirements (or "rules," as Cooper puts it in the above passage). And where we see "oughts" as articulating ideals, rather than as requirements, we are more readily willing to tolerate others' non-compliance and disagreementinstead of, say, taking others to be the proper targets of blame, resentment, or even retribution. Correspondingly, where "oughts" do not require capacities, skills, or qualities that we take to be very difficult to achieve or sustain in their own rights, there we see less leeway for excuses or lenience. And this evidently impacts how hard we try, or believe we must try, and expect others to try.

Contrary to what the second half of the quoted passage suggests, however, we cannot simply read off our demand-enablers or demand-waivers from our factual notions of what real people are like. Some of the reasons for this we have come across earlier on already, but there are further, perhaps more 
important reasons. Our conceptions of demand-enablers are normative, even if only implicitly so - that is, they are normative at least in virtue of their practical role and function, whether or not they are recognizable as normative by their linguistic surface. Any such conception singles out and privileges some subset of human characteristics, and a certain degree of their development, as prerequisites of the (at least minimally apt) pursuit of doing right and being good. For instance, even where we demand things apparently as basic and closely under our control as honesty, empathy, or charity, we presuppose that people sustain a sufficient degree of emotional and intellectual clarity, open-mindedness, self-control, courage, flexibility, and so forth, to realize what these virtues call for, what it would take to act on them in a given situation, and how they rank in relation to other normative considerations. These demand-enabling characteristics mark qualities that people can choose to harm or to cultivate, but that, we take it, they have reasons to value, and so should develop or protect, at least if and to the extent that the demands that are enabled by them have any importance. Thus, they mark what we might call proto-ideals: while they do not amount to full-blown substantive ideals of moral agency in their own right, they specify basic ingredients, and necessary conditions, of what, we take it, it is like to be someone who succeeds in the pursuit of doing right and being good - that is, on at least some conception of what doing right and being good actually requires, which may or may not be our own. ${ }^{11}$

This suggests two additional respects in which demand-waivers are implicitly normative. On the one hand, what level of human development we require people to bring to the pursuit of doing right and being good partly depends, too, on our substantive ethical views, or at least that subset of such views that, we take it, reflect necessary components of any genuine ethical code. After all, only if we have a conception of what the business of doing right and being good actually asks of people will we be able to know what people need to be like in order to participate in that business. On the other hand, conceptions of demand-enablers and demand-waivers play an important role in the economy of ethical recognition. If indeed they play the role of proto-ideals, then being recognised by others as an agent who passes the threshold of having the ability of doing right and being good, while it might amount to a mere fraction of the kind of ethical recognition people usually desire to enjoy, is a key prerequisite for one's recognition as a fully developed, well-functioning moral agent. Being seen as failing to pass that threshold, accordingly, would involve a considerable loss of value or standing in the eyes of others: it means to be seen as someone who does not even qualify as a participant in the pursuit of integrity, far from actually excelling in this pursuit. The importance that this recognition has for individuals, in turn, is mirrored in what they expect of others. That is, even where we expect others to disagree deeply with our substantive ethical views, including, as it were, our more fully developed conceptions of virtue, perfection, and goodness of character, we nevertheless expect them to show at least some concern for the development and protection of an ability for doing 
right and being good in themselves or others; and we tend to condemn practices, beliefs, and social, political, economical, and other contexts that harm or destroy this ability in people. ${ }^{12}$

These stipulative remarks, while plausible, do not aspire to do justice to the depth and great variety of considerations that reasonable people can reasonably bring to bear on the selection of demand-waivers and demand-enablers. However, my aim here is not to provide a comprehensive account of that complex issue. Instead, I follow the limited aim of making plausible (i) that there are normative and ethical issues at stake in determining what kind of "cannot" should play the role of a demand-waiver, and (ii) that placing the threshold of demand-waivers hence does not depend on logic and the facts alone, but depends, too, on normative considerations that at least sometimes are ethical in nature. On this view, it is not only, but also, our norms, values, or ideals by which we determine, or have reasons to determine, within what scope "oughts" are intelligible — and this, I suggest, is so even (and especially) if the relevant facts are at hand.

\section{A Very Modest Normativism}

What kind of view does all this suggest? The factualist policy, we have seen, in effect interprets OIC as a maxim such as

FP: As it is not the case that $\mathrm{X}$ ought to $\varphi$ if $\mathrm{X}$ cannot $\varphi$, we should not assume that $X$ ought to $\varphi$ if there is good reason to believe that $X$ cannot $\varphi$.

We have seen, too, that there are reasons to follow this policy whenever there are standing reasons to believe that $\mathrm{X}$ cannot $\varphi$, and hence it seemed to be the case that normativism is both unreasonable and irrelevant. What has now emerged, however, suggests a more differentiated picture. Even if there is a sense of "can" in which it is true that X cannot $\varphi$, a full justification of waiving "oughts" for the reason that X cannot $\varphi$ (in the corresponding sense) needs to establish why, in the case at hand, the threshold of demand-waivers should be placed accordingly. And showing this, I have argued, requires normative considerations, and, at least in the case of some "oughts," ethical considerations. It thus seems that the following doxastic policy would reflect the true nature of applications of OIC — we might think of it as a very modest kind of normativism:

MN: If we ought to (or may) place the threshold of demand-waivers accordingly, then we should not assume that $\mathrm{X}$ ought to $\varphi$ if there is good reason to believe that $\mathrm{X}$ cannot $\varphi$.

MN significantly elevates the role normative considerations play in our usage of OIC, and, accordingly, in the justification of this usage. In this, it goes beyond factualism. But MN does not share the problem of a pure form of normativism: as it does not simply apply OIC along the lines of the maxim "ought 
therefore can," it steers clear of the potential unreasonableness of this maxim. $\mathrm{MN}$ is normativist in the more modest sense of taking it that the selection of the appropriate kind of "can" is a normative issue (that is, within the scope of "oughts" that meet the threshold of logical possibility). According to MN, then, where we non-trivially use OIC as the rule "cannot therefore not ought", we do not comb out "oughts" simply on the basis of facts and logic, but also draw on normative considerations.

Now, how deeply ethicised a corresponding, normatively transparent practice of applying OIC would turn out to be depends on what it takes to cash out the antecedent of MN in normative argument. This can vary from case to case depending on, for instance, what the relevant normative claims prescribe, what ethical and non-ethical costs and benefits adopting the proposed set of demand-waivers would have, and how much ethical background consensus a selection and application of demand-waivers can draw on. But nothing rules out that disagreements about the intelligibility of "oughts" will turn into cases in which the desirability, acceptability, or normative justifiability of the supposed demand-waiver thresholds become the crux of the issue, thus turning what initially might appear to be a dispute about facts and logic into a substantive ethical dispute about whatever values, norms, or proto-ideals might underpin the corresponding demand-waiver threshold. In fact, it seems that we have reason to expect agreement about the intelligibility of "oughts" — and so about the bounds of normativity - to hinge on agreement about normative, and, more narrowly, ethical issues, e.g., about the demandingness and content of our proto-ideals. Where no such agreement is available, applications of OIC are likely to be as controversial as these normative or ethical issues themselves. If that is right, then the discursive purchase and value of OIC will essentially depend on the availability of a suitable normative, if not ethical, background consensus.

Let me conclude my discussion with a conjecture about over-demanding "oughts." Above, I assumed that logically possible "oughts" that prescribe what average people are psychologically, intellectually, or physically incapable of doing are not necessarily unintelligible, even though they might be unreasonable on other grounds. Obviously, such "oughts" would be pointless, if not irrational, as attempts to guide actual choices. ${ }^{13}$ Leaving this fact aside, however, there also is something ethically troublesome about them. Here is a suggestion as to what that troubling element might be. Where such "oughts" express (alleged) ethical requirements - as opposed to what Cooper calls "ideals"- they seem to conflict with what appears to be an often-endorsed, deeply entrenched substantive ethical idea. We might dub it the idea of "normative availabilism":

NA: Ethical requirements should be such that average people who conscientiously engage in the pursuit of doing right and being good have a fair chance of genuinely participating and succeeding in that pursuit. 
NA in effect requires our proto-ideals to allow average people the opportunity to access the good of qualifying as a full participant in the pursuit of doing right and being good. Thus, NA asks us to construe of only those capacities and qualities as proto-ideals, or as prerequisites of a participation in the pursuit of doing right and being good, that average people have a fair chance of showing. In the light of such a view, then, there are reasons to reject ethical requirements as unduly demanding that presuppose demand-enablers that would force us to distinguish between two moral classes within the class of average people: namely, (i) the class of people who in their own right and other things being equal "can" do what they are ethically required to do, and who thus do not fail to deserve the good of ethical recognition, and (ii) the class of people who in their own right and other things being equal "cannot" do what they are ethically required to do, and who hence fail to deserve the good of ethical recognition. And such a two-class system would run up against the often-shared conviction that average people who conscientiously try hard should have equal, or at least relevantly similar, opportunity to access fundamentally important goods - such as the good of qualifying as a genuine participant in the pursuit of doing right and being good. According to NA, therefore, we should not accord to "oughts" the status of ethical requirements - as opposed to ideals or supererogative principles - where acting on them would suppose special talents, capacities, or skills, so that average people who conscientiously try to participate in that pursuit actually have a fair chance to earn recognition as such participants. If this makes sense, it might somewhat flesh out a view that has surfaced several times above: namely, the view that our proto-idealswhich, in turn, impose constraints on what we can construe of as ethical requirements - are in their own right subject to ethical constraints. Perhaps it is an ethical, potentially egalitarian idea such as normative availabilism that stands behind the widely endorsed view that we ought not to ethically require what average people who conscientiously try cannot actually do.

\section{Notes}

For helpful feedback, criticism, and discussions on various earlier versions of this paper I am indebted to James P. Griffin, Dale Smith, Micah Schwartzman, Simon Wigley, W. Todd Davidson, Andreas Muth, an anonymous referee of Dialogue, and in particular Sabine I. Jentsch and Kinch Hoekstra.

1 In recent debate, Streumer (2007), Vranas, Stern, and Howard-Snyder are amongst those who defend that (some kind of) "ought" entails or implies "can." Hare argues that the link between "ought" and "can" is not one of entailment, but is presuppositional. See Hare, p. 54f.; Cooper shares this view. I shall return to a presuppositional interpretation later. Sinnott-Armstrong argues that the link between "ought" and "can" is extra-logical, and that "ought" conversationally implicates "can." Brown and Kekes, by contrast, see OIC as expressing an ethical view of some special kind.

2 For the purposes of my argument, not much depends on how exactly we distinguish between the factual and the normative, so long as we agree that there are factual 
views and that at least some normative views, or "oughts," seek to guide an agent's choices. However, we might think of views as factual if their best linguistic expression is descriptive in meaning, and we might think of views as normative if their best linguistic expression is prescriptive in meaning. On this usage, views can be factual without being empirical, while a view can express an "ought" to which OIC applies even if it does not contain the word "ought."

3 For a brand of factualism: see Griffin (1992) and (1996), pp. 96f. and 104ff. For Griffin, purported moral standards that require what is beyond human capacities are not simply wrong, but fail to be genuine standards. On this basis, he rejects direct and indirect forms of utilitarianism as they require moral agents to engage in types of moral thinking which, in Griffin's view, are beyond what moral agents are capable of. As Robert Stern has argued, this in effect applies a version of OIC to utilitarian standards: see Stern, esp. pp. 44ff. As Griffin seems to suppose that the relevant human limitations would have to be determined on factual, non-moral grounds, this application of OIC seems to fit the factualist pattern. Factualism is not restricted to moral theory and practice. There are also epistemological instances: see Bykvist and Hattiangadi, esp. p. 279.

4 On one reading, Kant adopted a form of normativism. As Stern suggests, Kant endorsed OIC and reasoned from what we morally ought to do toward a view of what we, as moral agents, are capable of doing. This would employ the idea that we must be capable of doing what we (allegedly) ought to do as a tool to work out the capacities which we must have, or must take ourselves to have, insofar as we take ourselves to be moral agents. See Stern (2004), p. 60. As it is worth observing, this form of normativism is of a heuristic, (inter-)subjective variety. As Kant highlights in the third part of the Groundwork, we are bound to think of ourselves as reasonable beings (or, more generally, as normative beings), and thus must presuppose the capacities that this requires. See Kant, pp. 52ff. However, this does not mean that we actually have the presupposed capacities as it is possible that we presuppose falsehoods or things that cannot be shown to be true or false. For a sophisticated recent brand of normativism, see Vranas, esp. pp. $171 \mathrm{ff}$.

5 Hare, p. 54. See also Hampshire's and Hare's views in Hampshire, Maclagan, and Hare, esp. pp. 162ff. and 201ff.; see also Cooper, esp. pp. $46 \mathrm{ff}$.

6 The following might help to clarify things. If we represent "ought" as "O" (for the deontic "obligatory"), claims to the effect that someone ought to $\varphi$ can be represented as " $\exists \mathrm{x} O(\varphi \mathrm{x})$ " (there is a person such that it is obligatory for this person to $\varphi)$. In the case of an internal negation, then, " $\exists \mathrm{x} \mathrm{O}(\varphi \mathrm{x})$ " is transformed into " $\exists \mathrm{x}$ $\mathrm{O}(\neg \varphi \mathrm{x})$ " (there is a person such that it is obligatory for this person not to $[\varphi]$ ); thus, the negator covers what is claimed to be obligatory (or what is prescribed, demanded, required, and so forth). In the case of external negations, however, the negator covers also the operator: " $\exists \mathrm{x} \mathrm{O}(\varphi \mathrm{x})$ " thus yields " $\exists \mathrm{x} \neg[\mathrm{O}(\varphi \mathrm{x})]$ " (there is a person such that it is not the case that [it is obligatory for this person to $\varphi$ ]). Accordingly, an external negation waives or suspends an "ought," or registers that an "ought" does not apply, rather than prescribes the opposite. Correspondingly, external negations do not carry over prescriptive force: while "It is not the case that X 
ought to $\varphi$ " is prescriptive if read as stating an internally negated "ought," it is not prescriptive if read as stating an externally negated "ought." If that is right, then OIC, while it allows us to move from "X can't $\varphi$ " to "It is not the case that X ought to $\varphi$ " (given an appropriate conception of "can"- - on this matter, see below), does not breach Hume's rule: as the latter is externally negated, no prescriptive "ought" is inferred from a descriptive "can." To reconcile OIC with that rule, therefore, it is not necessary to interpret it as a substantive moral principle. This has sometimes been overlooked, e.g., by Brown, esp. 207f., and Collingridge, esp. pp. $350 \mathrm{f}$.

7 Hare's view marks a strong performative reading of OIC. Sinnott-Armstrong advances a much weaker performative reading when he argues that "ought" conversationally implicates “can." See Sinnott-Armstrong. As Streumer shows, though, this reading seems too weak. If "ought" conversationally implicates "can," then speakers can without oddity cancel the implicature by expressing that they do not believe that the relevant others can do what they prescribe. But if Paul says (i) "You, Betty, ought to $\varphi$," but then adds (ii) "I (Paul) believe that you (Betty) cannot $\varphi$," then this is odd - at least if Paul utters (i) to prescribe that Betty engage in $\varphi$-ing [things might be different if (i) was a different kind of speech-act]. See Streumer (2003), p. 221.

8 Kekes, p. 459. Others, too, have noted the issue but then have set aside any deeper discussion of implications - even though the issue is crucial for the full appraisal of the usage we make of OIC. See, e.g., Howard-Snyder, esp. 234, and Brown, p. 213.

9 Montefiore, esp. p. 33.

10 Thus, I partially agree with Cooper, p. 48. Cooper in effect construes of "oughts" that prescribe the empirically impossible as intelligible, but sees them as irrational. I agree that they can be intelligible, whether or not they necessarily are irrational, and hence take it that empirical possibility cannot mark a minimal threshold that all "oughts" must meet. I shall come back to this issue below.

11 Hampshire appears to overlook this point. He insists that ordinary people usually have some more or less vague views of what "normal people" usually are like, and he seems to take it to be a purely descriptive, factual matter to invoke such views for the purposes of OIC. However, not only is it not a merely factual matter to invoke one set of capacities or skills as demand-enablers rather than another; it is also the case that our notions of the level and kind of capacities or skills morality requires are partly normative in their own right. Cf. his remarks in Hampshire, Maclagan, and Hare, pp. 170f.

12 This brings in an issue that goes beyond the purposes of my discussion, but that should nevertheless at least be touched on now. As an anonymous reviewer has pointed out, demand-enabling characteristics might not necessarily be proto-ideals, but might instead be substantive ideals of moral agency - that is to say, they might sometimes mark conceptions of moral perfection in their own right. I agree that ethical codes are possible that treat the same set of characteristics as demandenabling and as marking substantive moral ideals. I conjecture, however, that such codes are the exception rather than the rule: we often place the threshold for demand-enabling characteristics much lower than the threshold for achieving 
moral ideals, or moral perfection. The distinction between proto-ideals and ideals attempts to reflect the difference between (i) the set of characteristics that qualifies us as participants in a practice and (ii) the set of characteristics that qualifies us as excelling in that practice. Evidently, we can agree at the level of (i) while disagreeing at the level of (ii). E.g., our views of what it requires to be an outstanding chess player might differ, while we agree about what it requires to play chess in the first place. Applied to the ethical case, if we disagree about the standards of rightness and goodness, we will disagree about what it requires in a person to achieve moral perfection; but we can nevertheless agree about what it requires in a person to qualify as a committed moral agent. Now, our proto-ideals tend to be less demanding than do our substantive moral ideals, at least where we leave room for such disagreement: after all, even where we deeply disagree with other committed moral agents about the standards of rightness and goodness, and hence about what it involves and requires to achieve moral perfection, we nevertheless can, and often do, recognize these others as committed moral agents.

13 Still, we should not dismiss such "oughts" as irrational altogether. Over-demanding "oughts" might not primarily amount to attempts to guide choices. And even if we focus on "oughts" the speaker intends to guide choices, a logically possible but otherwise unfulfillable prescription can have, as Cooper puts it, a "second life," e.g., by "changing its character and ceasing to be a prescription or by prescribing some possible action as a substitute" (Cooper, p. 48.) One such "substitute," it seems to me, can be located at the level of evaluative responses and attitudes. Unfulfillable prescriptions can have the simple upshot of asking us to not content ourselves with, or even welcome, the conditions that render them unfulfillable; and even where these conditions are taken to be unchangeable by us or others - as they would be in the case of what I refer to above as tragic normsthe recommendation can be to deplore or resent the way things are anyway. At least in the case of tragic norms, this amounts to a substantive, evaluatively selective outlook that has, or can have, a considerable impact on how people act and look at things.

\section{References}

Brown, J.

1977 "Moral Theory and the Ought-Can Principle." Mind 86: 206-23.

Bykvist, K. and A. Hattiangadi

2007 “Does Thought Imply Ought?” Analysis 67: 277-85.

Collingridge, D. G.

1977 “' 'Ought-Implies-Can’ and Hume's Rule.” Philosophy 52: 348-51.

Cooper, N.

1966 “Some Presuppositions of Moral Judgements." Mind 75: 45-57.

Griffin, J. D.

1992 "The Human Good and the Ambitions of Consequentialism." In The Good Life and the Human Good, ed. E. F. Paul, F. D. Miller, and J. Paul, 118-32. Cambridge: Cambridge University Press. 
1996 Value Judgement. Oxford: Oxford University Press.

Hampshire, S., W. G. Maclagan, and R. M. Hare

1951 "Symposium: Freedom of the Will." Proceedings of the Aristotelian Society, Supplementary Volume 25: 161-216.

Hare, R. M.

1963 Freedom and Reason. Oxford: Oxford University Press.

Howard-Snyder, F.

2006 “' ‘Cannot' Implies 'Not Ought'.” Philosophical Studies 130: 233-46.

Kant, I.

1997 Groundwork of the Metaphysics of Morals. Trans. by M. Gregor [1785]. Cambridge: Cambridge University Press.

Kekes, J.

1984 “' 'Ought Implies Can' and Two Kinds of Morality.” The Philosophical Quarterly 34: 459-67.

Montefiore, A.

1958 “' 'Ought' and 'Can'.” The Philosophical Quarterly 8: 24-40.

Sinnott-Armstrong, W.

1984 “ 'Ought' Conversationally Implies 'Can'.” Philosophical Review 93: 249-61.

Stern, R.

2004 “Does 'Ought' Imply 'Can'? And Did Kant Think It Does?" Utilitas 16: 42-61.

Streumer, B.

2003 “Does 'Ought' Conversationally Implicate 'Can'?” European Journal of Philosophy 11: 219-28.

2007 "Reasons and Impossibility." Philosophical Studies 136: 351-84.

Vranas, P. B. M.

2007 “I Ought, Therefore I Can.” Philosophical Studies 136: 167-216. 